\title{
Asymmetric catalysis with chiral organocopper-copper arenethiolates
}

\author{
Gerard van Koten \\ Department of Metal-Mediated Synthesis, Debye Institute, Utrecht University, \\ Padualaan 8, $3584 \mathrm{CH}$ Utrecht, The Netherlands
}

\begin{abstract}
Novel copper arenethiolates, $[\mathrm{CuSAr}]_{n}$, which have as a special feature the presence of a potentially coordinating ortho amino group, $\mathrm{CH}\left(\mathrm{R}^{\prime}\right) \mathrm{NMe}_{2}$, have been developed as catalysts for the conjugate 1,4-addition of Grignards to Michatel acceptors. The arenethiolate anion appears to behave as an excellent non-transferable group. By selecting a chiral orthe amino group $\left(\mathrm{CuSAr}^{*} ; c . g, \mathrm{R}^{\prime}=\mathrm{Me}\right)$ a chiral copper arene thiolate catalyst is obtained. The reaction of methylmagnesium iodide with benzylidene acetone and $3 \mathrm{~mol} \%$ CuSAr* in toluene takes place with complete conversion to the 1,4-addition product and an e.e. of $76 \%$. The preferred mode of addition is the simultaneous addition of $R^{t} M g X\left(R^{t}\right.$ is a transferable group) and benzylidene acetone to a toluene solution of $[\mathrm{CuSAr}-(R)]_{3}$ in benzene/toluene. Model studies revealed that the $[\mathrm{CuSAr}-(R)]_{3}$ aggregate (X-ray and NMR) reacts with $\mathrm{R}^{\prime} \mathrm{MgX}$ to a new aggregate $\left[\mathrm{CuR}^{\prime}\right]_{4}\left[\mathrm{Mg}\left(\mathrm{SAr}-(R)_{2}\right]_{2}\right.$ (X-ray and NMR) from which the kinetic intermediate is produced through interaction with the substrate. The selective formation of both the heterocuprate [CuR'] $[\mathrm{Mg}$ (SAr$(R))_{2}$ ] and the kinetic intermediate, which most probably has the seemingly simple dinuclear structure I (see Scheme 8), are the first examples of selective self-assembly of mononuclear units $\mathrm{RCu}$, CuSAr and $\mathrm{R}^{\mathrm{L}} \mathrm{MgX}$ to one larger aggregate rather than to a number of different mixed aggregates with almost the same thermodynamic stability. It is proposed that coordination of the ortho amino group (of SAr) to the $\mathrm{MgX}$ unit stabilizes the kinetic intermediate. The Michael acceptor anchors via $\mathrm{Mg}-\mathrm{O}=\mathrm{C}$ coordination which brings the $\mathrm{C}=\mathrm{C}$ part of the enone-substrate in the right position for alkene-copper coordination and subsequent transfer of the transferable group $\mathrm{R}^{\mathrm{l}}$.
\end{abstract}

\section{INTRODUCTION}

The in situ generation of organocopper reagents via transmetallation reactions of organometallic reagents with copper salts is a commonly used protocol in synthetic organic chemistry (ref. 1). In many cases stoichiometric amounts or excess of cuprates $\mathrm{R}_{2} \mathrm{CuZ}(\mathrm{Z}=\mathrm{Li}$ or $\mathrm{MgX}$ ) have to be applied to achieve complete conversion of the substrate in, for example, conjugate 1,4-additions and cross coupling reactions. Sometimes the organometallic compound (usually $\mathrm{RMgX}$ ) can be used in the presence of catalytic amounts of a copper sait, which is of importance from an economic (no waste of the transferable group $R^{\mathfrak{l}}$ ) as well as an

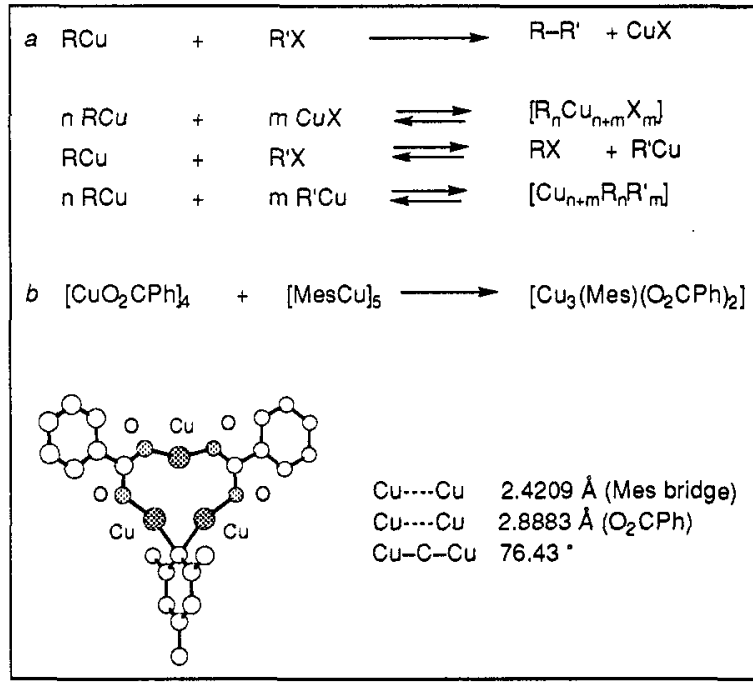

Scheme 1a. The cross coupling reaction and three interfering equilibria which cause a lowering of the selectivity. b. Selective formation of a trinuclear copper species through self assembly (Scc ref. 2 for a discussion of the bonding in such species). 
An important feature of these reactions is the formation of metal (copper) salts in addition to the products. The notion that these salts can interfere with the nature and thus the reactivity of the starting copper reagent is not widespread among organic synthetic chemists (ref.2). The effect these salts may have in copper mediated reactions is best demonstrated with the cross coupling reaction, see Scheme $1 \mathrm{a}$, in which in addition to R-R' also CuX is formed (refs. 2 and 3). When the cross coupling step is the fastest reaction the formation of $\mathrm{CuX}$ will be no problem for the selectivity of the reaction. However, we amply demonstrated in separate (model) reactions in which pure $\mathrm{RCu}$ was mixed with $\mathrm{CuX}$ that new copper aggregates $\left[\mathrm{R}_{\mathrm{n}} \mathrm{Cu}_{\mathrm{n}+\mathrm{m}} \mathrm{X}_{\mathrm{m}}\right]$ may form having the organo group and the halide bound to the same central copper core. Similarly mixed organocopper aggregates can be formed via selective inter-aggregate exchange equilibria (ref.4). Accordingly when the latter equilibria have similar kinetics as the cross coupling reaction itself an unselective reaction may occur or there is no reaction at all because of the sometimes higher kinetic stability of the aggregates. A striking example of the high selectivity that can be encountered in exchange reactions between copper species is shown in Scheme 1b. Mixing copper benzoate tetramer with mesitylcopper pentamer leads to the selective formation of the tricopper species $\left[\mathrm{Cu}_{3}(\mathrm{Mes})\left(\mathrm{O}_{2} \mathrm{CPh}\right)_{2}\right]$ even though many other species could be formed (ref.5). This points to the occurrence of a self-assembly process which obviously derives its high selectivity from the steric and electronic information present in the anions as well as of the specific coordination properties of the copper(I) cation. We have evidence that these processes involve the dissociation of the homo-aggregates into mono-nuclear species which subsequently assemble to the larger hetero-aggregates. One aim in our organocopper chemistry is to learn to understand these processes to the effect that we can channel reactions with copper reagents, along the desired reaction path.

Similar observations concerning the selectivity of these self-assembling processes have been made during our study of the formation of neutral cuprates in solution, see Scheme 2. When the pure organocopper compound $\left[\mathrm{Cu}\left\{\mathrm{C}_{6} \mathrm{H}_{4} \mathrm{CH}_{2} \mathrm{NMe}_{2}-2\right\}\right]_{4}$ is mixed with the corresponding organolithium compound $\left[\mathrm{Li}\left\{\mathrm{C}_{6} \mathrm{H}_{4} \mathrm{CH}_{2} \mathrm{NMe}_{2}-\right.\right.$ $2]_{4}$ of all possible aggregates only one aggregate $\left[\mathrm{Cu}_{2} \mathrm{Li}_{2}\left\{\mathrm{C}_{6} \mathrm{H}_{4} \mathrm{CH}_{2} \mathrm{NMe}_{2}-2\right\}\right]_{4}$ is formed again most probably via self-assembly of mononuclear copper and lithium species (ref.6). The characterisation and bonding in this species have been extensively discussed by us and others and our cuprate has been frequently used as a general model for neutral cuprates, e.g. for explaining the reactivity of $\mathrm{Cu}_{2} \mathrm{Li}_{2} \mathrm{Me}_{4}$. It may suffice here to remark that, $a$. the copper and

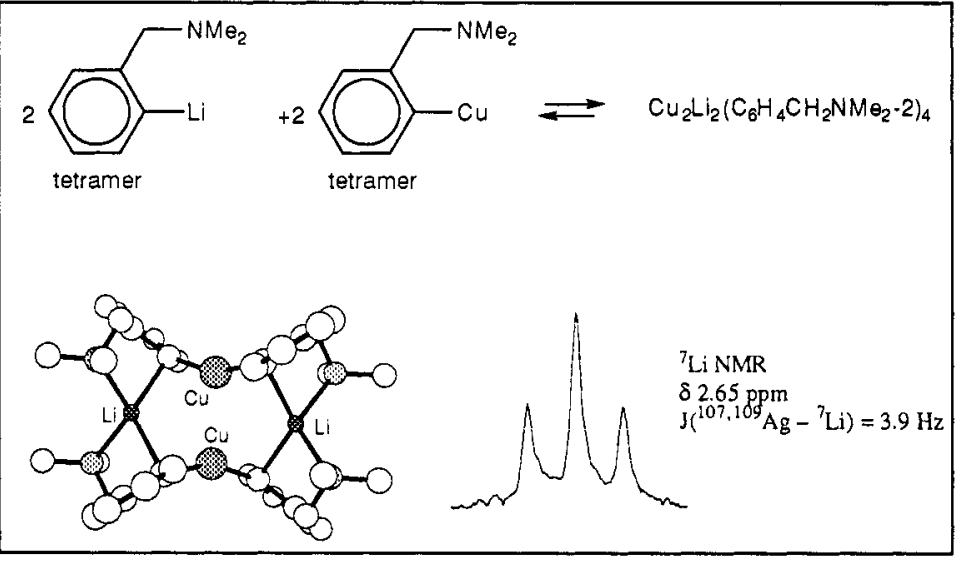

Scheme 2. Formation of the neutral homocuprate $\left[\mathrm{Cu}_{2} \mathrm{Li}_{2}\left(\mathrm{C}_{6} \mathrm{H}_{4} \mathrm{CH}_{2} \mathrm{NMe}_{2}-2\right)\right]_{4}$, its structure in the solid state (ref. 6 ) and unambiguous evidence of the existence of the aggregate in solution from ${ }^{7} \mathrm{Li}$ NMR of the corresponding argentate (ref. 7).

lithium atoms are mutually trans positioned, $b$. the aggregate comprises units $\left[\mathrm{CuR}_{2}\right]^{-}$and lithium cations, which are solvated either by intramolecular amine coordination or by coordination of an external ether solvent molecule $\left(c f .\left[\mathrm{Cu}_{2} \mathrm{Li}_{2} \mathrm{Ph}_{4} \cdot\left(\mathrm{Et}_{2} \mathrm{O}\right)_{2}\right]\right.$ ) (ref. 6) and finally, $c$. the structural features encountered in the solid state, see $\mathrm{X}$-ray of $\left[\mathrm{Cu}_{2} \mathrm{Li}_{2}\left\{\mathrm{C}_{6} \mathrm{H}_{4} \mathrm{CH}_{2} \mathrm{NMe}_{2}-2\right\}\right]_{4}$ (Scheme 2 ) is retained in solution as could also be unambiguously proven in solution for the corresponding argentate compound $\left[\mathrm{Ag}_{2} \mathrm{Li}_{2}\left\{\mathrm{C}_{6} \mathrm{H}_{4} \mathrm{CH}_{2} \mathrm{NMe}_{2}-2\right\}\right]_{4}$ (see ${ }^{7} \mathrm{Li}$ NMR spectrum in Scheme 2 which proves that each lithium has two silver neighbours, ref. 7). From these examples we can conclude that in situ generation of organocopper and -cuprate reagents can be made selective when we would know more about the rules that affect 
the self-assembling process in these reactions. Finally, there is one other aspect that so far has received little attention, i.e. the fact that ligands as well as substrate molecules will influence the self-assembling process by being incorporated as nucleophiles (electron-pair donating molecules) in the aggregates and the reactive species. With considerations outlined above in mind we have embarked on a model study of the role of transferable and non-transferable groups in the (enantioselective) 1,4-addition reaction of $\mathrm{RMgX}$ reagents to enones catalyzed by a suitable, chiral organic-copper salt.

Following the general requirements for a non-transferable group outlined in Scheme 3 we selected the arenethiolate anion, which has as a special feature a potentially coordinating ortho amino group $\mathrm{CH}\left(\mathrm{R}^{\prime}\right) \mathrm{NMe}_{2}$ that can be either chiral ( $\mathrm{R}^{\prime}$ $=\mathrm{Me}$ ) or achiral $\left(\mathrm{R}^{\prime}=\mathrm{H}\right)$ (ref.8). Accordingly this arenethiolate anion can bind not only via its anionic $\mathrm{S}$ atom but additionally also with the amine $\mathrm{N}$-donor atom. As indicated in Scheme 3 the S- and $\mathrm{N}$-donor atom sites can be connected with carbon atom linkers with various kinds of flexibility and electronic properties and can give rise to the formation of either six- or

\section{Conditions for the non-transferable group}

1 The transferability has to be low.

2 The stability of the formed cuprate has to be high.

3 The disproportionation equilibrium has to be (completely) at the side of the heterocuprate.

On these requirements CuSAr* has been selected; i.e.<smiles>CSc1ccccc1C(Br)N(C)C</smiles>

1 trimer: a $R^{\prime}=\mathrm{Me}$, $(R)$-enantiomer; $\mathbf{b}^{\prime} \mathbf{R}^{\prime}=H$<smiles>CN(C)c1ccccc1SCl</smiles>

2 trimer

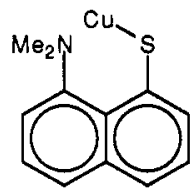

3 nonamer

Scheme 3. The N,S-coordinating non-transferable ortho aminoarenefive-membered chelate rings by thiolate anion, [SAr]". coordination to reactive metal centres, either copper or copper and Li or MgX in cuprates. Key features of this amine group are that it can assist in the formation and stabilization of reactive (key-)intermediates and that it can be used for the transfer of stereochemical information during the binding process of the substrate to the copper or cuprate intermediates and the subsequent transfer of $\mathrm{R}^{\mathrm{t}}$ to the substrate.

In the next two paragraphs the coordination/organometallic chemistry of copper arenethiolates and the cuprate species will be sketched and the successful application of the copper arenethiolates as catalysts in organic synthesis discussed.

\section{STRUCTURE AND REACTIVITY OF COPPER ARENETHIOLATES}

A series of copper arenethiolates with built-in amine substituents have been prepared of which the three examples shown in Scheme 3 are important for the present discussion. In order to have full control over the nature and amount of the metal salts present in subsequent organic reactions, mediated/catalyzed by our copper arenethiolates, a synthetic procedure was developed which avoids the formation of metal salts and involves the reaction of the pure trimethylsilyl arenethiolate with copper chloride, see Scheme 4 (ref.9). This procedure has the advantage that the only other product formed with the pure copper arenethiolate is volatile trimethylsilyl chloride. Most probably already in this reaction the amino group plays an important role as the reaction of copper chloride with parent trimethylsilyl phenylthiolate is not

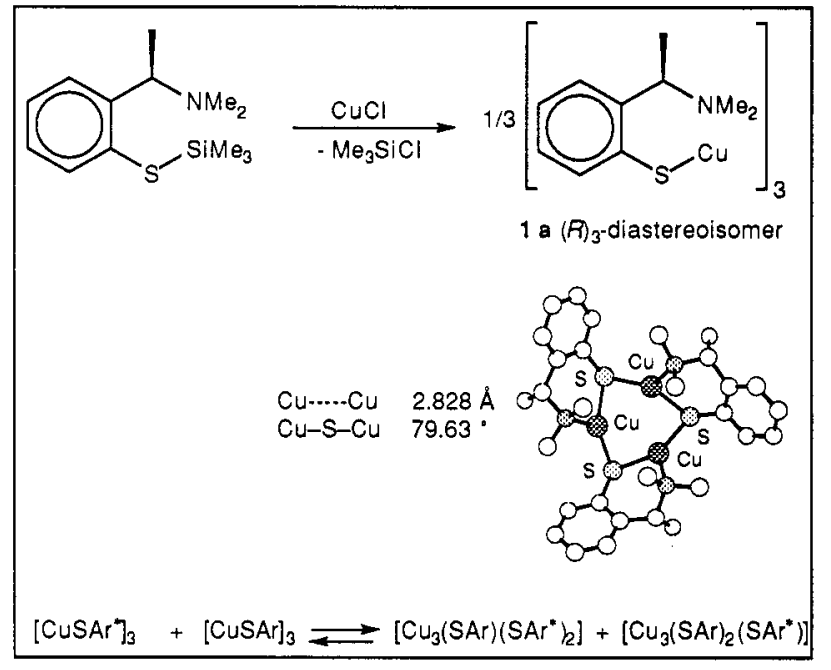

Scheme 4. 
clean at all. A further, initially surprising, effect of the presence of the amino group are the different physical properties of these copper arenethiolates; whereas the parent compound, CuSPh, is very insoluble, the three copper arenethiolates shown in Scheme 3 are all soluble in various organic solvents. A possible reason for this is that the ortho amino substituted arenethiolates have discrete aggregate structures both in solution (determined by cryoscopy) and the solid state (ref.8). The structure of $\left[\mathrm{Cu}\left(\mathrm{SC}_{6} \mathrm{H}_{4}\left(\mathrm{CHMeNMe}{ }_{2}\right\}-2-(R)\right)\right]_{3}(\mathbf{1} \mathrm{a}$, see Scheme 4) shows some important features, which also have been encountered in structures of related copper arenethiolates: $i . e$., an aggregate structure formed because the thiolate $\mathrm{S}$ atoms each bridge two copper atoms, and the occurrence of intramolecular $\mathrm{Cu}-\mathrm{N}$ coordination. Furthermore the acute $\mathrm{Cu}-\mathrm{S}-\mathrm{Cu}$ ' bond angle of $79.63(7)^{\circ}$ and the short $\mathrm{Cu}$.. $\mathrm{Cu}$ distance of 2.828 (1) $\AA$ in 1 a have been interpreted by us in terms of two-electron three-center SCuCu' binding, i.e. the anionic N,S-ligands contribute four electrons (one electron pair via the $\mathrm{N}$ and one via the $\mathrm{S}$ atom) in their binding to copper aggregates [CuSAr] $]_{n}$ (for an extensive discussion of this aspect, see ref.8). Finally it is important to note that $1 \mathrm{a}$ has been synthesized from the pure $(R)-\mathrm{C}_{6} \mathrm{H}_{5} \mathrm{CH}(\mathrm{Me}) \mathrm{NMe}_{2}$ enantiomer and accordingly it is the $(R)_{3}$-diastereoisomer which is present in solution and which has been crystallized. Copper arenethiolate 1a has as a further chiral element the anti-clockwise $\mathrm{Cu}-\mathrm{N}$ coordination for the respective ortho amino groupings providing six-membered CuSCCCN chelate rings. The "side"-view of the structure of $1 \mathrm{a}$ clearly shows that the six-membered $\mathrm{Cu}_{3} \mathrm{~S}_{3}$-ring has a chair conformation with equatorially bonded aryl groupings. In solution this stereoisomer with $C_{3}$ symmetry exists together with a $C_{1}$ conformer that has a $\mathrm{Cu}_{3} \mathrm{~S}_{3}$ chair with two aromatic rings in equatorial positions and one in an axial position $\left(C_{3} / C_{1}\right.$ molar ratio is $3 / 1$ in toluene) (ref.8). Recently we established by mass spectrometry that the trinuclear aggregates undergo inter-aggregate exchange in benzene to the effect that an equimolar solution of $1 \mathrm{a}$ and $\mathbf{1 b}$ in benzene affords an equilibrium mixture of the corresponding homo- and heteroarenethiolatocopperisomers, see Scheme 4. This finding underlines the proposal made earlier that the trinuclear aggregates are the thermodynamically more stable species and are the result of self-assembling (aggregation) of CuSAr units. Any change in the aryl portion of the SAr anion may influence other aggregates to become more stable, e.g., 2 (Ar is dimethylaniline) is also a [CuSAr] $]_{3}$ aggregate whereas 3 , in which $\mathrm{Ar}$ is a naphthylamine, is present both in solution and in the solid state as a nonamer [CuSAr$]_{9}$ (ref.10). This piece of evidence is relevant for the mechanistic proposal of the conjugate addition reactions catalyzed by $\mathbf{1 a}$ and $\mathbf{1 b}$, vide infra.

We studied in separate experiments what happens to these copper arenethiolates in the presence of pure organocopper, organolithium, organomagnesium halide and diorganomagnesium complexes (ref.11). In all reactions selective assembling to new mixed species was observed and we could further prove experimentally that in the presence of twoelectron-donating ligands $\left(e . g ., \mathrm{PPh}_{3}\right)$ or substrate (e.g., enones) selective re-assembling takes place to new species comprising copper cations, arenethiolato- and organo-anions, and the neutral two-electron-donating ligand. A striking example of this fascinating assembling process is shown in Scheme 5.

When mesitylcopper is mixed with $\mathbf{1 b}$ in benzene a new tetranuclear copper aggregate $\left[\mathrm{Cu}_{4}(\mathrm{SAr})_{2}(\mathrm{Mes})_{2}\right](4)$ is formed. The structures of 4 in solution (cryoscopy and ${ }^{13} \mathrm{C}$ and ${ }^{1} \mathrm{H}$ $\mathrm{NMR}$ ) and in the solid state (X-ray, see Scheme 5) are similar (ref.11). The aggregate consists of four copper atoms in a butterfly arrangement in

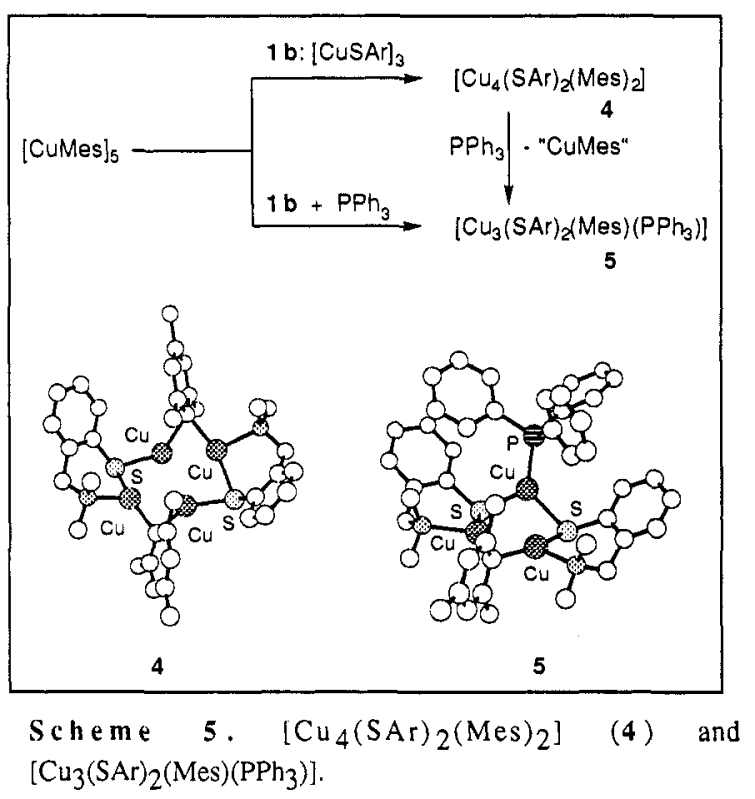


which two mesityl groups bridge opposite $\mathrm{Cu} . . \mathrm{Cu}$ edges $(2.39 \AA)$ and the two SAr groups bridge, through the S-anion, the remaining $\mathrm{Cu} . . \mathrm{Cu}$ edges $(2.74 \AA)$ and also coordinate intramolecularly through the amino groups to opposite copper atoms (for further details see ref.11). Both the mesityl and the SAr groups bridge between the copper atoms in a fashion typical for electron-deficient two-electron three-centre bonding. The structure clearly shows the presence of two di- and two tri-coordinate copper atoms; a commonly encountered structural motive in organocopper chemistry, e.g. $\left[\mathrm{Cu}_{4}(\mathrm{Mes})_{4}(\mathrm{THT})_{2}\right]$ (ref.12) and $\left[\mathrm{Cu}_{4}\left(\mathrm{C}_{6} \mathrm{H}_{4} \mathrm{Me}-2\right)_{4}\left(\mathrm{SMe}_{2}\right)_{2}\right]$ (ref.13). Even more interesting is that these basic structural features are also present in some arylcuprates, e.g.the earlier discussed neutral homocuprate $\left[\mathrm{Cu}_{2} \mathrm{Li}_{2}\left(\mathrm{C}_{6} \mathrm{H}_{4} \mathrm{CH}_{2} \mathrm{NMe}_{2}-2\right)_{4}\right]$ (see Scheme 2). Thus, structures of the homoaryl- and the hetero(aryl)arenethiolate-coppers are directly related to those of the homoarylcuprate in that the three- (or four-) coordinate copper centres are equivalent to the more highly coordinated lithium ions in the $\mathrm{Cu}_{2} \mathrm{Li}_{2}$ four-membered ring. Accordingly the structure of 4 can also be considered as an aggregate comprising two anionic (Mes) $\mathrm{Cu}(\mathrm{SAr}$ ) (cuprate) species held together by two (amino) Cu cations.

In the presence of a Lewis base, $\mathrm{PPh}_{3}$ in Scheme 5, one $\mathrm{Cu}(\mathrm{Mes})$ unit is expelled and a trinuclear copper aggregate, $\left[\mathrm{Cu}_{3}(\mathrm{SAr})_{2}(\mathrm{Mes})\left(\mathrm{PPh}_{3}\right)\right](5)$, formed (ref.11). The same aggregate is formed directly when mesitylcopper, the copper arenethiolate, and triphenylphosphine are mixed in benzene. All three copper atoms in $\mathbf{5}$ are three-coordinate (sum of the angles is $359^{\circ}$ ). The $\mathrm{Cu}_{2} \mathrm{~S}$ units in $\mathbf{5}$ have acute $\mathrm{Cu}-\mathrm{S}$ $\mathrm{Cu}$ angles $\left(76^{\circ}\right)$ and short $\mathrm{Cu}$...Cu distances $\left(2.77 \AA\right.$ ) just like the electron-deficient $\mathrm{Cu}_{2} \mathrm{~S}$ units in 4 . This fascinating species comprises a $\mathrm{Cu}_{3}$ array containing three different ligands and anions.

Finally, Scheme 6 shows the result of the reaction of $1 \mathrm{a}$ with dimesitylmagnesium, which provides the novel cuprate $\left[\mathrm{Cu}_{4}(\mathrm{Mes})_{4}\right]\left[\mathrm{Mg}\left(\mathrm{SAr}^{*}\right)_{2}\right]_{2}, 6$ (ref.11). Contrary to our expectation that the softer acid, i.e. the copper ion, would bind stronger to the thiolate- $S$ atom than to the aryl- $C_{i p s o}$, we find that the structure consists of a central $\left[\mathrm{Cu}_{4}(\mathrm{Mes})_{4}\right]$ core to which to opposite copper atoms the $\left[\mathrm{Mg}\left(\mathrm{SAr}_{2}\right)_{2}\right]$ units are coordinated via the $\mathrm{S}$ atoms. Also in this structure the two- and three-coordinate copper atom motive can be recognized. Alternatively we can envisage this structure also as containing anionic (Mes) $\mathrm{Cu}(\mathrm{SAr})$ (cuprate) species and $\mathrm{Mg}(\mathrm{SAr})$ cations.

From this structural work the following conclusions can be drawn:

$i$. the anionic, ortho amino substituted arenethiolate ligands, SAr, are tightly bonded to copper(I) even when heterocuprate species are formed with Grignard reagents,

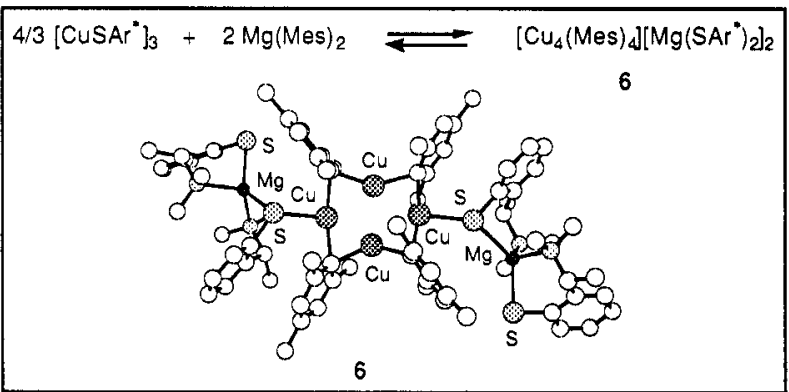

Scheme 6. $\left[\mathrm{Cu}_{4}(\mathrm{Mes})_{4}\right]\left[\mathrm{Mg}(\mathrm{SAr})_{2} \mathrm{l}_{2}\right.$.

ii, a commonly encountered bonding mode for the SAr ligand involves two-electron three-center bonding via the anionic S-donor atom to either two coppers or one copper and a lithium or magnesium cation. The amine donor coordinates via a six-membered chelate ring to copper (homocopper species) or to lithium and magnesium (heterocuprate species), i.e. the monoanionic SAr ligand in these cases functions as a four-electron donating ligand,

iii, introduction of a chiral amine substituent in the copper arenethiolate is feasible and leads to the diasteroselective formation of the CuSAr* aggregates, and

$i v$, the ideas developed earlier concerning the application of selective self-assembly in copper and cuprate chemistry by selecting organocopper, (organic-)copper salts and lithium or magnesium reagents which are properly tuned to produce one well-defined pre-catalytic species have led to the synthesis and isolation of a series of novel heterocopper and cuprate compounds.

In the next section it will be shown that some of the cuprate aggregates are real pre-catalytic species that react selectively with substrates to form kinetically active intermediates/aggregates in which product formation occurs. 


\section{COPPER ARENETHIOLATES AS CATALYST IN CONJUGATE ADDITIONS}

So far the copper salts $\mathrm{CuX}$ applied in copper-mediated organic synthesis make use of monodentate anions $\mathrm{X}(e . g$., $\mathrm{CN}$, halide, $\mathrm{SPh}, \mathrm{C} \equiv \mathrm{CR}$ ") as non-transferable groups (ref.1). The arenethiolates we have developed in our study are the first non-transferable anions for which it has been unambiguously demonstrated that they can act as multidentate ligands; i.e., they are capable of binding the Lewis-acidic metal centre $\left(\mathrm{Mg}^{++}\right.$or $\left.\mathrm{Li}^{+}\right)$to the thiolate SCu entity via S-bridge bonding and so stabilize this $\mathrm{Cu}-\mathrm{S}-\mathrm{Mg}$ or $\mathrm{Cu}-\mathrm{S}-\mathrm{Li}$ interaction via additional $\mathrm{N}$-metal coordination (ref.14).

In this report we will concentrate on a discussion of our first results with conjugate 1,4-addition reactions of Grignard reagents with benzylidene acetone (BA) catalyzed by $\mathrm{CuSAr}$ (see also ref. 15). All experiments have been carried out under standard conditions; i.e., at $0{ }^{\circ} \mathrm{C}, 0.125 \mathrm{M} \mathrm{R} \mathrm{t} \mathrm{MgX}, 3 \mathrm{~mol} \%$ CuSARr* and using addition method $\mathrm{C}$ (vide infra). Scheme 7 shows the results of the three different reaction procedures followed. In all cases CuSAr* catalyses the complete conversion of BA into the 1,4addition product. However, only in the case of addition method $\mathrm{C}$ was a significant e.e. of $76 \%$ of one enantiomer $(S)$ obtained. From this result various conclusions can be drawn. Firstly, the formation of the kinetic cuprate intermediate with coordinated enone as well as the subsequent conversion to the magnesium enolate (with re-formation of free CuSAr*) is fast. Secondly, all copper cations are efficiently bonded to the arenethiolate anion as the occurrence of any $\mathrm{MgX} / \mathrm{Cu}$ exchange would immediately produce the homocuprate $\mathrm{Me}_{2} \mathrm{MgCuX}$ which would produce the conjugate addition product without e.e. Thirdly, excess MeMgX (method B) leaves the regioselectivity unaffected but does destroy the enantioselectivity of the reaction.

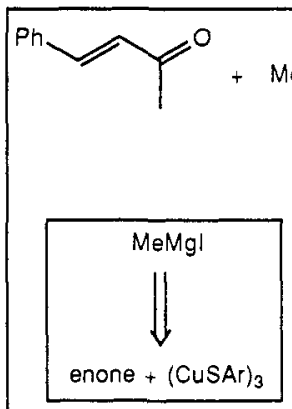

(A)

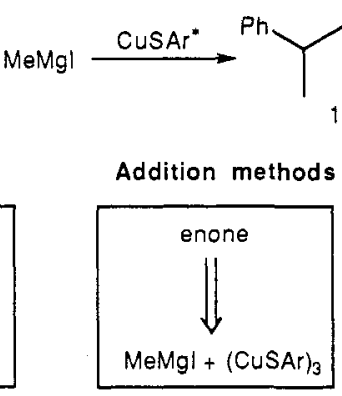

(B)

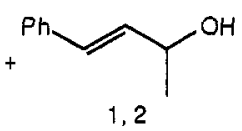

1,2

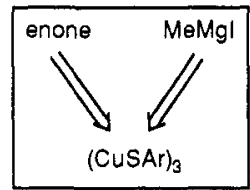

(C)

Method A : Large amount of enolate formation, e.e. $=47 \%$

Method B : Complete 1,4-addition, e.e. $=0 \%$

Method C : Complete 1,4-addition, e.e. $=76 \%$ + 2 eq. $\mathrm{Me}_{3} \mathrm{SiCl}, 75 \%$ 1,4-addition, $76 \%$ e.e.

Scheme 7 Influence of the order of addition of the reagents and catalyst on the enantioselectivity.

Finally, the magnesium enolate

formed does not interfere with the copper containing aggregates, i.e., the enolate anion does not give rise to self-assembly of aggregates that can compete with the assembly of the kinetic intermediate from which product formation occurs. This may also explain the fact that the presence of one or two equivalents of $\mathrm{Me}_{3} \mathrm{SiCl}$ during the reaction leaves both the regio- and stereoselectivity unaffected. (This may suggest that the "pacification" of the enolate anion by silylation is the main reason that in conjugate 1,4-addition reactions the addition of $\mathrm{MeSiCl}$ is sometimes effective. (ref.10))

On the basis of the above observations and conclusions we have formulated structure $\mathbf{I}$ shown in Scheme 8 for the kinetically active organo-arenethiolatocuprate-enone intermediate (refs.10 and 14). The proposed structural features of $\mathbf{I}$ are corroborated by the outcome of several experiments. The use of $\mathrm{R}^{\mathrm{t}} \mathrm{Mg}$-iodide or -trifluoromethanesulfonate is essential for the stereoselectivity of the reaction: with $\mathrm{MeMg}$ chloride the e.e. drops to $20 \%$. Moreover, in the presence of one equivalent of $\mathrm{BF}_{3}$ the e.e. becomes literally $0 \%$. These observations point to the importance of $\mathrm{O}-\mathrm{Mg}$ coordination of the enone for the stereoselectivity of the conjugate addition step in the reaction. When $\mathrm{X}$ is a weak nucleophile (I or Otf anion) this $\mathrm{Mg}-\mathrm{O}$ coordination will be maximal (i.e., the Lewis acidity of $\mathrm{Mg}$ is highest) and consequently the positioning of the enone in the intermediate. It is obvious that $\mathrm{BF}_{3}$ by its strong interaction with the 
enone oxygen atom will completely block the enone O-donor atom site for coordination to $\mathrm{Mg}$. The enantioselectivity is highest in solvents of low polarity and poor coordinating ability. For example, in THF the e.e. is zero and this indicates that THF competes most probably with both the enone-O-to- $\mathrm{Mg}$ and the intramolecular $\mathrm{Mg}-\mathrm{N}$ coordination resulting in a less rigid stereochemistry of the enone-cuprate intermediate. We obtain further information concerning the enone coordination to the organomagnesium-arenethiolate cuprate species from the use of BA substrates that are para-substituted with an electron donating or withdrawing functional group. The preliminary results of this study (that introduction of an electron-withdrawing substituent, i.e. $\mathrm{Cl}$, decreases the e.e. to 63 $\%$ ) can be used to corroborate the view that

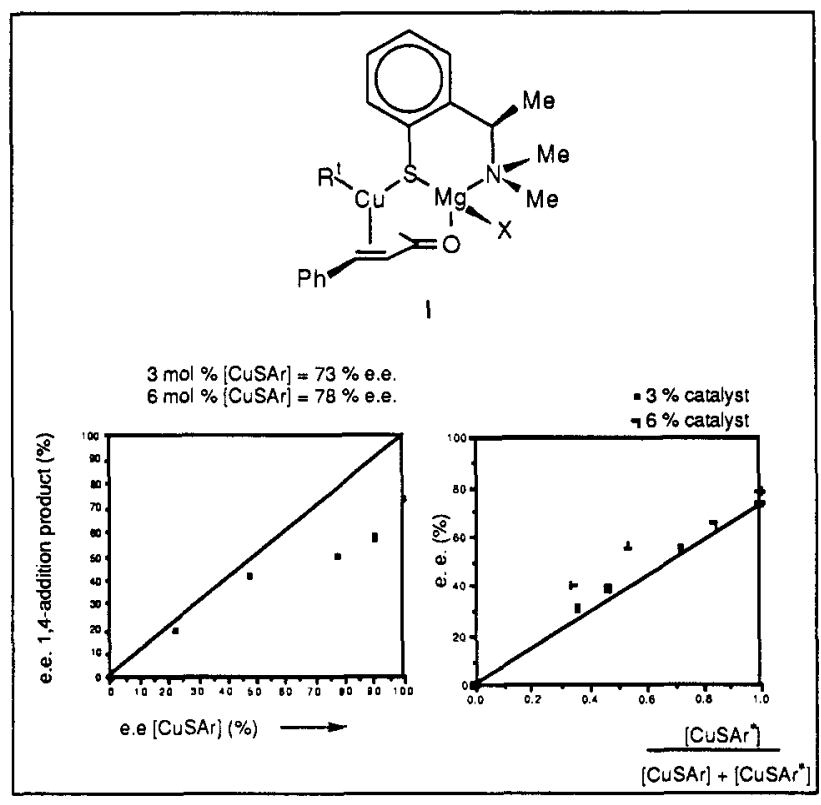

Scheme 8 Influence of the enantiomeric purity of CuSAr* on the product e.e. such a substituent lowers the back-bonding component in the alkene-Cu interaction and thus the rigidity of the cuprate-enone intermediate. An intriguing observation is the influence of the e.e. of the catalyst versus the e.e. of the product, see Scheme 8. (The catalyst e.e. was obtained by mixing of the appopriate amounts of the enantiomerically pure [CuSAr- $(R)]_{3}$ and $[\operatorname{CuSAr}-(S)]_{3}$ compounds (ref.10)). Whereas with up to about $50 \%$ e.e. of CuSAr* the e.e. of the 1,4-product follows a linear correlation, at higher catalyst e.e.'s large deviations are found. So far we do not have an explanation for this phenomenon. One possible explanation we investigated is the occurrence of a pre-equilibrium involving multinuclear species with different kinetic stability. However, the following result excludes this possibility. In a series of experiments we used a catalyst combination comprising a given amount of enantiomerically pure CuSAr*, (which produces the 1,4-product with $76 \%$ e.e.) and achiral CuSAr, (which produces the racemic mixture). It has to be recalled that the CuSAr and CuSAr* trinuclear copper species undergo rapid interaggregate exchange, see Scheme 4. The result is shown in Scheme 8 and is compatible with the view that mononuclear $\left[\mathrm{R}^{\mathrm{t}} \mathrm{MgX}-\mathrm{CuSAr} *\right]$ species are involved as the kinetic intermediates.

At present our research is directed to the study of the scope and the selectivity of our CuSAr catalyst as well as to the further optimalization of the N,S motive in the arenethiolate anion. This involves the study of both the synthesis and the structural features of a whole range of copper arenethiolates with different $\mathrm{N}, \mathrm{S}$ stereochemistry, $c f .1,2$, and 3 in Scheme 3. Recently, Pfaltz and Zhou already demonstrated the potential of our approach; their chiral orthooxazolinearenethiolatecopper catalyst likewise containing the N,S structural motive is nicely active in conjugate additions to cyclic enones, see Scheme 9 , yielding the addition product with $87 \%$ e.e. (ref. 16). In a joint project

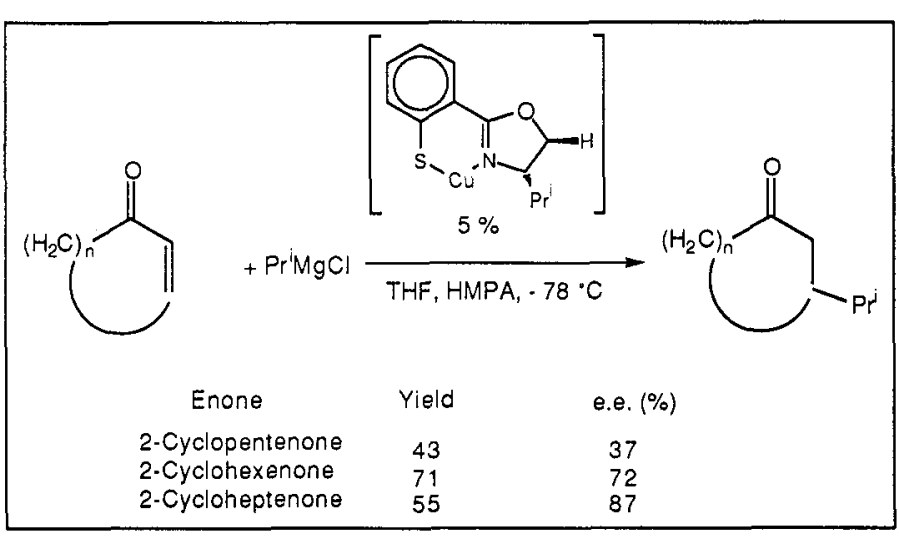

Scheme 9. Use of CuSAr${ }^{*}$ (see Rel.16) for the conjugate addition of $\operatorname{Pr}^{\mathrm{i}} \mathrm{MgCl}$ to cyclic enones. 
with the group of Krause we recently found that achiral CuSAr ( 1 b) is also effective as a catalyst in 1,6-conjugate additions to acceptor enynes, see Scheme 10 (ref.17). Whereas the traditional cuprate reagents had to be used in stoichiometric amounts providing sometimes a mixture of products, the CuSAr-catalysed reactions require only one equivalent of $\mathrm{RLi}$ and show clean, regioselective 1,6-conversions.

\section{CONCLUSIONS}

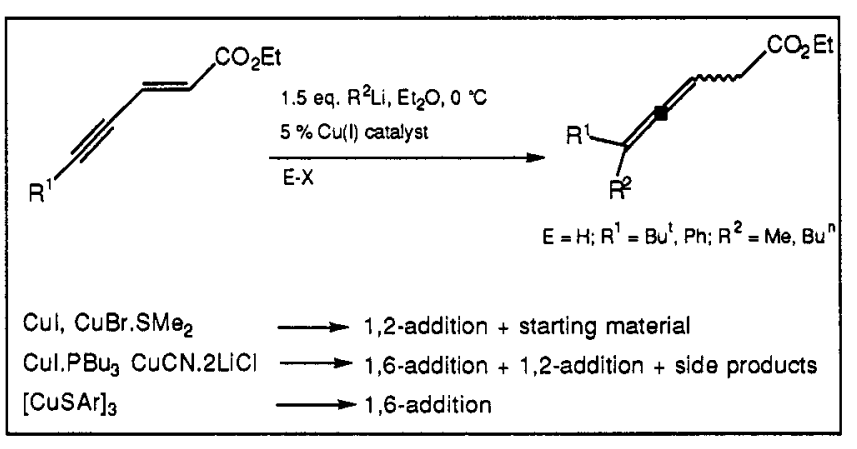

Scheme 10 Regioselective 1,6-addition reaction catalysed by CuSAr (1 b).

The ortho amine substituted arenethiolate copper compounds CuSAr are versatile catalysts in the 1,4 conjugate addition of Grignard reagents to enones. When chiral CuSAr${ }^{*}$ is used e.e.'s of up to $80 \%$ have been achieved. The kinetic intermediate is assembled from CuSAr, RMgX and enone entities. The single mononuclear CuSAr entities emerge from dissociation of larger CuSAr aggregates. In the absence of enone the CuSAr and $\mathrm{RMgX}$ entities self-assemble to mixed aggregates with a well-defined structure and stereochemistry (e.g., $\left.\left[\mathrm{Cu}_{4}(\mathrm{Mes})_{4}\right]\left[\mathrm{Mg}\left(\mathrm{SAr}^{*}\right)_{2}\right]_{2}\right)$.

\section{ACKNOWLEDGEMENTS}

I am greatly indebted to my dedicated and talented former and present co-workers. In particular I like to thank Dr. J.T.B.H. Jastrzebski and Dr. D.M. Grove for their help in the preparation of this manuscript and Mrs. M. van Klaveren and Mr. M.D. Janssen who are presently active in the CuSAr-organocopper field. The Netherlands Foundation of Chemical Research (SON) and The Netherlands Organization for Scientific Research, the EC and the Utrecht University are gratetfully acknowledged for their financial support.

\section{REFERENCES}

1. G.H. Posner, Org. React. 19, 1 (1972); B.H. Lipshutz, Synthesis 325 (1987); B.H. Lipshutz and S. Sengupta, Org. React. 41,135 (1992).

2. G. van Koten and J.G. Noltes, Comprehensive Organomel. Chem. 14, 709 (1982); G. van Koten and J.G. Noltes, J. Org. Chem, 42, 2705 (1977); G. van Koten and J.T.B.H. Jastrzebski, Tetrahedron Mini-Symposium in Print, 4 5, 569 (1989).

3. G. van Koten, J.T.B.H. Jastrzebski and J.G. Noltes, J.Org. Chem. 4 2, 2047 (1977).

4. R.W.M. ten Hoedt, G.van Koten and J.G. Noltes, J. Org. Chem. 133, 113 (1977); G. van Koten and J.G. Noltes, J.Org. Chem. 8 4, 129 (1975).

5. H.L. Aalten, G. van Koten, K. Goubitz and C.H. Stam, J. Chem. Soc., Chem. Commun, 1252 (1985); H.L. Aalten, G. van Koten, K. Goubitz and C.H. Stam, Organometallics, 8, 2294 (1989).

6. G. van Koten and J.G. Noltes, J. Chem. Soc. Chem. Commun, 940 (1972); G. van Koten and J.G. Noltes, J. Amer. Chem. Soc., 101, 6593 (1979).

7. G. van Koten, J.T.B.H. Jastrzebski, C.H. Stam and N.C. Niemann, J. Amer. Chem. Soc., 106, 1880 (1984); J.T.B.H. Jastrzebski, G.van Koten, M. Konijn and C.H. Stam, J. Amer. Chem Soc., 10 4, 5490 (1985); G. van Koten, J.T.B.H. Jastrzebski, F. Muller and C.H. Stam, J. Amer. Chem. Soc., 107,697 (1985).

8. D.M. Knotter, G. van Koten, H.L. van Maanen, D.M. Grove and A.L. Spek, Angew. Chem., 101,351 (1989); D.M. Knotter. H.L. van Maanen, D.M. Grove, A.L. Spek and G. van Koten, Inorg. Chem., 30, 3309 (1991).

9. D.M. Knotter, M.D. Janssen, D.M. Grove, W.J.J. Smeets, E. Horn, A.L. Spek and G. van Koten, Inorg. Chem., 30, 4361 (1991).

10. M. van Klaveren, M.D. Janssen and G. van Koten, to be published.

11. D.M. Knotter, W.J.J. Smeets, A.L. Spek and G. van Koten, J. Amer. Chem. Soc., 11 2, 5895 (1990); D.M. Knotter, D.M. Grove, W.J.J. Smeets, A.L. Spek and G. van Koten, J. Amer. Chem. Soc., 11 4, 3400 (1992).

12. E.M. Meyers, S. Gambarotta, C. Floriani, A. Chiesi-Villa and C. Guastini, Organometallics, 8, 1067 (1989).

13. B. Lenders, W.J.J. Smeets, P. van der Sluis, D.M. Grove, A.L. Spek and G. van Koten, Organometallics, 10,786 (1991).

14. G. van Koten, J. Organometal. Chem., 400, 283 (1990).

15. F. Lambert, D.M. Knotter, M.D. Janssen, M van Klaveren, J. Boersma and G. van Koten, Tetrahedron Asymmetry, 2 , 1097 (1991).

16. Q-L. Zhou and A. Pfaltz, Tetrahedron Lell. in print.

17. A. Haubrich, M. van Klaveren, G. van Koten, G. Handke and N. Krause, J. Org. Chem. 58, 5849 (1993). 